Thorax (1976), 31, 730.

\title{
Arterial blood gas tensions, hydrogen ion, and electroencephalogram during sleep in patients with chronic ventilatory failure
}

\author{
A. G. LEITCH, L. J. CLANCY, R. J. E. LEGGETT, P. TWEEDDALE, \\ P. DAWSON, and J. I. EVANS \\ Department of Medicine, Royal Infirmary and Department of Psychiatry, Royal Edinburgh Hospital, \\ University of Edinburgh
}

\begin{abstract}
Leitch, A. G., Clancy, L. J., Leggett, R. J. E., Tweeddale, P., Dawson, P., and Evans, J. I. (1976). Thorax, 31, 730-735. Arterial blood gas tensions, hydrogen ion, and electroencephalogram during sleep in patients with chronic ventilatory failure. We have studied arterial $\mathrm{Po}_{2}, \mathrm{PCO}_{2}$, and hydrogen ion and electroencephalogram during sleep in 10 patients with stable severe chronic respiratory failure. As a group the patients slept badly. Sleep was associated with a worsening of hypoxia and no significant change in $\mathrm{PCO}_{2}$ and $\mathrm{H}^{+}$. Two patients were restudied, receiving oxygen therapy overnight. Both had improved sleep but one, who had an intact hypoxic drive to breathing, developed marked hypercapnia and acidosis when his $\mathrm{Po}_{2}$ was restored to normal during sleep; the other, who had no hypoxic drive to breathing, developed no more hypercapnia or acidosis during sleep when breathing oxygen than when breathing air. Oxygen therapy may improve sleep disturbance in these patients, but its effect on the drive to breathing during sleep should be considered if severe hypercapnia and acidosis are to be avoided.
\end{abstract}

Hypoxia, hypercapnia, and acidosis (Mangold et al., 1955; Birchfield, Sieker, and Heyman, 1958; Robin et al., 1958; Sieker, Heyman, and Birchfield, 1960; Bülow, 1963; Bristow et al., 1969; Townsend, Prinz, and Obrist, 1973) associated with a reduction in the ventilatory response to inhaled $\mathrm{CO}_{2}$ and alveolar ventilation (Birchfield et al., 1958; Reed and Kellogg, 1958; Robin et al., 1958; Bellville et al., 1959; Sieker et al., 1960; Bülow, 1963; Honda and Natsui, 1967) are known to occur during sleep in normal man. These arterial blood gas tensions may be exaggerated in patients with chronic ventilatory failure (Robin, 1958; Koo, Sax, and Snider, 1975) who already have a marked reduction in the ventilatory response to inhaled $\mathrm{CO}_{2}$ (Alexander et al., 1955; Flenley, Franklin, and Millar, 1970). We have examined the arterial blood gas tensions, $\mathrm{H}^{+}$, and EEG during sleep in patients with severe chronic ventilatory failure and cor pulmonale secondary to chronic airways obstruction.

\section{PATIENTS AND METHODS}

Eight male and two female patients, mean age $58 \cdot 6 \pm$ 5.8 (SD) years, who were being assessed for longterm oxygen therapy, were studied. None was obese and all had severe airways obstruction (mean $\frac{3}{5}$ $\mathrm{FEV}_{1.0} \quad 0 \cdot 57 \pm 0 \cdot 19$ 1) with hypoxia (mean $\mathrm{PaO}_{2}$ 웅 $6.8 \pm 0.7 \mathrm{kPa}$ ), hypercapnia (mean $\mathrm{PaCO}_{2} 7.6 \pm 1.0$ $\mathrm{kPa}$ ), polycythaemia (mean red cell mass $35 \pm 11$ 음 $\mathrm{ml} / \mathrm{kg}$ ), and pulmonary hypertension (mean pulmonary artery pressure $4.1 \pm 0.7 \mathrm{kPa}$ ). The steady state ventilatory response to inhaled $\mathrm{CO}_{2}$ was 3 markedly reduced in seven of the eight patients in $\delta$ whom it was measured (mean $5.25 \pm 3.01$ min $^{-1} \mathrm{kPa} ₹$ $\left.\mathrm{PaCO}_{2}{ }^{-1}\right)$. All were in a stable clinical state at the time $\mathrm{O}$ of the study. Nine patients routinely took digoxin and diuretics and seven used adrenergic bronchodilators. Two were receiving antibiotics and two a small dose of prednisolone during the study. Three patients had 0 received hypnotics ( 2 nitrazepam and 1 glutethi- N mide) but none was taken during the period of the N study. One patient continued to take meprobamate, $200 \mathrm{mg}$ three times a day, during the study.

As part of the assessment for long-term oxygen $\frac{0}{\mathbb{D}}$ therapy, an indwelling arterial catheter had pre- $\stackrel{?}{?}$ viously been inserted percutaneously by the Seldinger 0 technique in the brachial artery. Hypoxic drive to $\stackrel{0}{\circ}$ breathing was assessed in seven of the patients by measuring the fall in $\mathrm{PCO}_{2}$ during $5 \% \mathrm{CO}_{2}$ inhalation $\mathbb{\Phi}$ when the arterial $\mathrm{PO}_{2}$ was reduced from hyperoxic $\frac{\Omega}{\sigma}$ 
(mean $\mathrm{Po}_{2} 24 \cdot 8 \pm 2 \cdot 8(\mathrm{SD}) \mathrm{kPa}$ ) to hypoxic (mean $\mathrm{Po}_{2} 6 \cdot 7 \pm 0 \cdot 7 \mathrm{kPa}$ ) levels. Two patients did not reduce their $\mathrm{PCO}_{2}$ and were considered to have absent or markedly diminished hypoxic drive to breathing using this test. Five patients did reduce their $\mathrm{PCO}_{2}$ in response to the hypoxic stimulus (range of fall in $\mathrm{PCO}_{2} 0.5-1.3 \mathrm{kPa}$ ) and were considered to have a hypoxic drive to breathing.

The patients slept in a single quiet side room on the nights of the studies. At approximately 2200 hours electrodes were placed around the patients' eyes, under the chin, and on the head in the midline so as to record eye movements, muscle tone, and EEG during sleep (Evans et al., 1968). The electrodes were connected to a lengthy harness, which allowed the patient a very free range of movement, and eventually to a portable eight-channel electroencephalographic machine placed in the corridor outside the room. This ran continuously from approximately 2230 hours until the time that the patient indicated he wanted to stop, which was generally about $\mathbf{0 7 0 0}$ hours. At the times of starting and finishing an arterial blood sample, a signal was fed to the machine so that the type of sleep present at sampling could be accurately known. Sleep records were read by standard criteria (Rechtschaffen and Kales, 1968) and divided into stages of sleep. The analysis of sleep records consists of identifying successive stages of sleep according to the frequencies present in the EEG and the absence of other physiological changes. Stage 5 or REM sleep is indicated by a drop in muscle tone and the onset of large siccadic eye movements. The record is read as areas of change from one stage of sleep to another continuously throughout the night, and the values (Table II) are obtained by summing the amounts of each stage present over the whole night and measuring the latency of appearance of stage 2 sleep and REM sleep.

Arterial blood samples were taken through a 100 $\mathrm{cm}$ catheter connected to the arterial catheter. Control samples were obtained in duplicate with the patient awake and supine after 30 minutes in bed. The room was then darkened and blood samples were obtained thereafter at approximately half-hour intervals throughout the night, two final samples being taken as soon after the patient wakened as possible.

One patient with and one without a hypoxic drive to breathing were restudied overnight when oxygen therapy was being given at a flow rate of 2 litres $\mathrm{min}^{-1}$ by nasal catheters. The procedures were approved by the Hospital Ethical Committee, and informed consent was obtained from the patients before each study.

\section{RESULTS}

arterial $\mathrm{PO}_{2}$ (table I) $\mathrm{Po}_{2}$ fell significantly $(P<0.001)$ from a mean control value of $6.98 \pm 0.21$ (SEM) $\mathrm{kPa}$ to a mean value during sleep of $6 \cdot 31 \pm 0.28$ $\mathrm{kPa}$. The mean maximal fall in $\mathrm{Po}_{2}$ for the group of subjects was $1.2 \mathrm{kPa}$ (range $0.7-1.9 \mathrm{kPa}$ ).

$\mathrm{PO}_{2}$ was on average lower after the period of sleep (mean value $6 \cdot 70 \pm 0.28 \mathrm{kPa}$ ) but the difference was not significant. A fall in $\mathrm{Po}_{2}$ was usually seen within the first hour of sleep, but there was no consistent relationship between $\mathrm{Po}_{2}$, sleep stage or time after onset of sleep.

ARTerial PCO 2 (TABle I; Fig. 1) The mean $\mathrm{PCO}_{2}$ was $7 \cdot 71 \pm 0 \cdot 32 \mathrm{kPa}$ in the control period and $7 \cdot 94 \pm 0 \cdot 28$

T A B L E I

VALUES OF $\mathrm{PO}_{2}(\mathrm{kPa}), \mathrm{PCO}_{2}(\mathrm{kPa})$, AND $\mathrm{H}^{+}$IN 10 PATIENTS BREATHING AIR AND 2 PATIENTS BREATHING OXYGEN (2 LITRES/MIN) BEFORE, DURING, AND AFTER SLEEP

\begin{tabular}{|c|c|c|c|c|c|c|c|c|c|c|c|c|c|c|c|}
\hline \multirow[b]{3}{*}{ Subject } & \multicolumn{13}{|c|}{ Inspired Gas } & \multirow{2}{*}{\multicolumn{2}{|c|}{$\mathbf{O}_{\mathbf{a}}$}} \\
\hline & \multicolumn{13}{|c|}{ Air } & & \\
\hline & 1 & 2 & 3 & 4 & 5 & 6 & 7 & 8 & 9 & 10 & Mean & SEM & $\mathbf{P}^{1}$ & 6 & 9 \\
\hline $\begin{array}{l}\mathrm{Po}_{2} \text { values } \\
\text { Control } \\
\text { Lowest sleep } \\
\text { Mean sleep } \\
\text { Post sleep }\end{array}$ & $\begin{array}{l}7 \cdot 6 \\
6 \cdot 5 \\
7 \cdot 0 \\
7 \cdot 1\end{array}$ & $\begin{array}{l}7 \cdot 6 \\
6 \cdot 9 \\
7 \cdot 3 \\
6 \cdot 8\end{array}$ & $\begin{array}{l}7 \cdot 5 \\
5 \cdot 6 \\
6 \cdot 6 \\
7 \cdot 3\end{array}$ & $\begin{array}{l}7 \cdot 5 \\
6 \cdot 7 \\
7 \cdot 0 \\
7 \cdot 9\end{array}$ & $\begin{array}{l}7 \cdot 3 \\
6 \cdot 1 \\
6 \cdot 4 \\
6 \cdot 7\end{array}$ & $\begin{array}{l}7 \cdot 3 \\
6 \cdot 0 \\
7 \cdot 0 \\
7 \cdot 2\end{array}$ & $\begin{array}{l}6 \cdot 5 \\
5 \cdot 9 \\
6 \cdot 4 \\
7 \cdot 6\end{array}$ & $\begin{array}{l}6 \cdot 5 \\
4 \cdot 8 \\
5 \cdot 1 \\
5 \cdot 3\end{array}$ & $\begin{array}{l}6 \cdot 3 \\
4 \cdot 7 \\
5 \cdot 2 \\
5 \cdot 6\end{array}$ & $\begin{array}{l}5 \cdot 7 \\
4 \cdot 7 \\
5 \cdot 1 \\
5 \cdot 6\end{array}$ & $\begin{array}{l}6 \cdot 98 \\
5 \cdot 78 \\
6 \cdot 31 \\
6 \cdot 70\end{array}$ & $\begin{array}{l}0.21 \\
0.27 \\
0.28 \\
0.28\end{array}$ & $\begin{array}{l}<0.001 \\
<0.001 \\
\text { NS }\end{array}$ & $\begin{array}{r}11 \cdot 5 \\
8 \cdot 4 \\
11 \cdot 0 \\
8 \cdot 9\end{array}$ & $\begin{array}{l}10 \cdot 3 \\
10 \cdot 5 \\
11 \cdot 5 \\
10 \cdot 0\end{array}$ \\
\hline $\begin{array}{l}\mathrm{PCO}_{2} \text { values } \\
\text { Control } \\
\text { Highest sleep } \\
\text { Mean sleep } \\
\text { Post sleep }\end{array}$ & $\begin{array}{l}7 \cdot 2 \\
8 \cdot 4 \\
7 \cdot 9 \\
7 \cdot 3\end{array}$ & $\begin{array}{l}6 \cdot 3 \\
6 \cdot 8 \\
6 \cdot 6 \\
6 \cdot 5\end{array}$ & $\begin{array}{l}8 \cdot 1 \\
9 \cdot 2 \\
8 \cdot 8 \\
8 \cdot 4\end{array}$ & $\begin{array}{l}6 \cdot 4 \\
7 \cdot 1 \\
6 \cdot 5 \\
6 \cdot 3\end{array}$ & $\begin{array}{l}6 \cdot 9 \\
7 \cdot 7 \\
7 \cdot 4 \\
7 \cdot 1\end{array}$ & $\begin{array}{l}7 \cdot 7 \\
8 \cdot 4 \\
8 \cdot 1 \\
8 \cdot 0\end{array}$ & $\begin{array}{l}7 \cdot 9 \\
8 \cdot 3 \\
7 \cdot 8 \\
6 \cdot 9\end{array}$ & $\begin{array}{l}9 \cdot 5 \\
9 \cdot 3 \\
8 \cdot 8 \\
8 \cdot 7\end{array}$ & $\begin{array}{l}8 \cdot 5 \\
9 \cdot 3 \\
8 \cdot 9 \\
8 \cdot 9\end{array}$ & $\begin{array}{l}8 \cdot 7 \\
9 \cdot 2 \\
8 \cdot 6 \\
8 \cdot 3\end{array}$ & $\begin{array}{l}7 \cdot 71 \\
8 \cdot 36 \\
7 \cdot 94 \\
7 \cdot 63\end{array}$ & $\begin{array}{l}0 \cdot 32 \\
0 \cdot 29 \\
0 \cdot 28 \\
0 \cdot 29\end{array}$ & $\begin{array}{l}<0.001 \\
\text { NS } \\
\text { NS }\end{array}$ & $\begin{array}{r}8 \cdot 4 \\
11 \cdot 1 \\
9 \cdot 6 \\
9 \cdot 6\end{array}$ & $\begin{array}{l}7 \cdot 9 \\
8 \cdot 5 \\
8 \cdot 0 \\
8 \cdot 4\end{array}$ \\
\hline $\begin{array}{l}\text { pH values } \\
\text { Control } \\
\text { Highest sleep } \\
\text { Mean sleep } \\
\text { Post sleep }\end{array}$ & $\begin{array}{l}36 \\
42 \\
40 \\
40\end{array}$ & $\bar{z}$ & $\begin{array}{l}41 \\
44 \\
43 \\
39\end{array}$ & $\begin{array}{l}40 \\
43 \\
41 \\
40\end{array}$ & $\bar{z}$ & $\begin{array}{l}40 \\
45 \\
43 \\
42\end{array}$ & $\begin{array}{l}35 \\
36 \\
35 \\
30\end{array}$ & $\begin{array}{l}46 \\
45 \\
43 \\
42\end{array}$ & $\begin{array}{l}46 \\
49 \\
46 \\
47\end{array}$ & $\begin{array}{l}43 \\
43 \\
42 \\
41\end{array}$ & $\begin{array}{l}40 \cdot 9 \\
43 \cdot 3 \\
41 \cdot 6 \\
40 \cdot 1\end{array}$ & $\begin{array}{l}1 \cdot 5 \\
1 \cdot 3 \\
1 \cdot 1 \\
1 \cdot 7\end{array}$ & $\begin{array}{c}<0.05 \\
\text { NS } \\
\text { NS }\end{array}$ & $\begin{array}{l}46 \\
56 \\
51 \\
49\end{array}$ & $\begin{array}{l}46 \\
46 \\
45 \\
46\end{array}$ \\
\hline
\end{tabular}

${ }_{1} \mathrm{P}$ values refer to significance of differences from control or presleep values. 

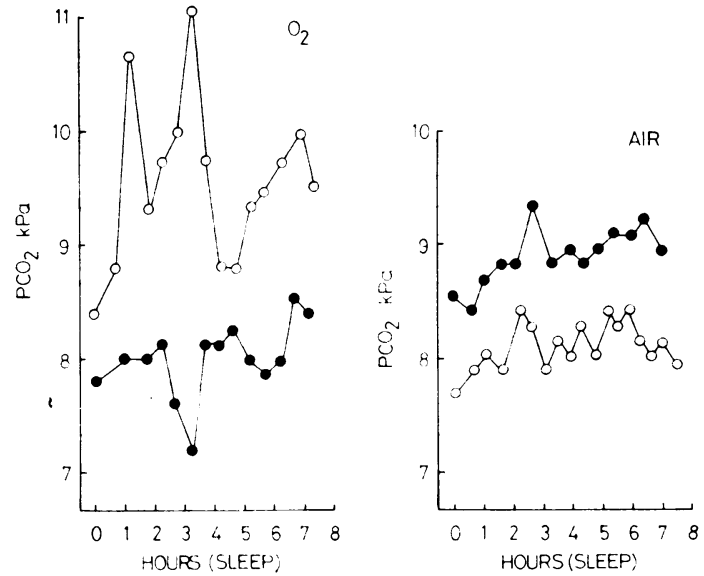

FIG. 1. Changes in arterial $\mathrm{PCO}_{2}$ overnight in patient $6(\mathrm{O})$ and patient 9 (O) when breathing oxygen (2 litres/min) and air. The mean sleep $\mathrm{Po}_{2}$ was $7 \cdot 0$ and $5 \cdot 2 \mathrm{kPa}$ on air and $11 \cdot 0$ and $11 \cdot 5 \mathrm{kPa}$ on oxygen for patients 6 and 9 respectively.

$\mathrm{kPa}$ during sleep, the difference not being significant. The mean rise in $\mathrm{PCO}_{2}$ during sleep was not related to the ventilatory response to inhaled $\mathrm{CO}_{2}$, and there was no consistent relationship between $\mathrm{PCO}_{2}$, sleep stage or time after onset of sleep. There was a significant $(\mathrm{P}<0.02)$ positive correlation on linear regression between mean sleep $\mathrm{PO}_{2}$ and the mean rise in $\mathrm{PCO}_{2}$ during sleep for each subject who had a demonstrable hypoxic drive.

ARTERIAL $\mathrm{H}^{+}$(TABLE I) The mean control value of $40.9 \pm 1.5 \mathrm{nmol} \mathrm{l}^{-1}$ and the mean sleep value of $41 \cdot 6 \pm 1 \cdot 1 \mathrm{nmol}^{-1}$ in the eight subjects studied did not differ significantly. The mean maximal rise observedo was $2 \cdot 5 \mathrm{nmol} \mathrm{l}^{-1}$.

ARTERIAL BLOOD GAS TENSIONS BREATHING OXYGEN $\stackrel{\mathbb{\complement}}{\Omega}$ (TABLE I; FIG. 1) The addition of 2 litres oxygen per® minute by nasal catheter to the inspired air in patients 6 and 9 produced marked differences in arterial $\mathrm{PCO}_{2}$. tensions and $\mathrm{H}^{+}$during sleep. Both patients were $\vec{\omega}$ restored to normoxia (mean sleep $\mathrm{Po}_{2}$ of 11.0 and $\stackrel{\circ}{\circ}$ $11.5 \mathrm{kPa}$ respectively), but patient 9 had a mean rise in $\vec{x}$ $\mathrm{PCO}_{2}$ of $0 \cdot 1 . \mathrm{kPa}$ in the course of the night whereas $\dot{\omega}$ patient 6 had a mean rise in $\mathrm{PCO}_{2}$ of $1.2 \mathrm{kPa}$ with a rise $-{ }_{-}^{-}$ in $\mathrm{H}^{+}$from 46 to $51 \mathrm{nmol} \mathrm{l}^{-1}$. The maximum rises in $\mathrm{PCO}_{2}$ and $\mathrm{H}^{+}$in patient 6 were $2.7 \mathrm{kPa}$ and 10 . $\mu \mathrm{mol} \mathrm{1}^{-1}$.

SLEEP (TABLE II) These patients proved to be very disturbed sleepers. As a group they slept a mean of $\frac{}{3}$ 304.2 min out of a possible mean 'in bed' time of $429.9 \mathrm{~min}$. Delay to sleep varied from 1.3 to $100 \mathrm{~min}$, and much of the loss of sleep was due to prolonged wakeful periods during the night so that the mean. percentage awake time was $30.9 \%$. Somewhat surprisingly for this age group (range 48-66 years), ¿ the amount of stage 4 orthodox sleep was greater than expected and reached values of over $11 \%$ total sleep in four subjects. However, it was absent in three other® subjects. Similarly, there was a great variation in $=$ REM (stage 5) sleep which was less than $10 \%$ in the three patients with a mean $\mathrm{Po}_{2}$ of less than $5.3 \mathrm{kPa} \supset$ during sleep, and over $20 \%$ total sleep in four othero patients. As a group these patients do not stay long in any stage of sleep and show frequent shifts between sleep stages which average $17 \cdot 1$ shifts per hour for the group, considerably more than we encountered in: normal subjects in this age group in our laboratory.

T A B L E I I

SLEEP ANALYSIS IN 10 PATIENTS BREATHING AIR COMPARED WITH 10 CONTROLS OF A SIMILAR AGE (Williams et al., 1972) (see text)

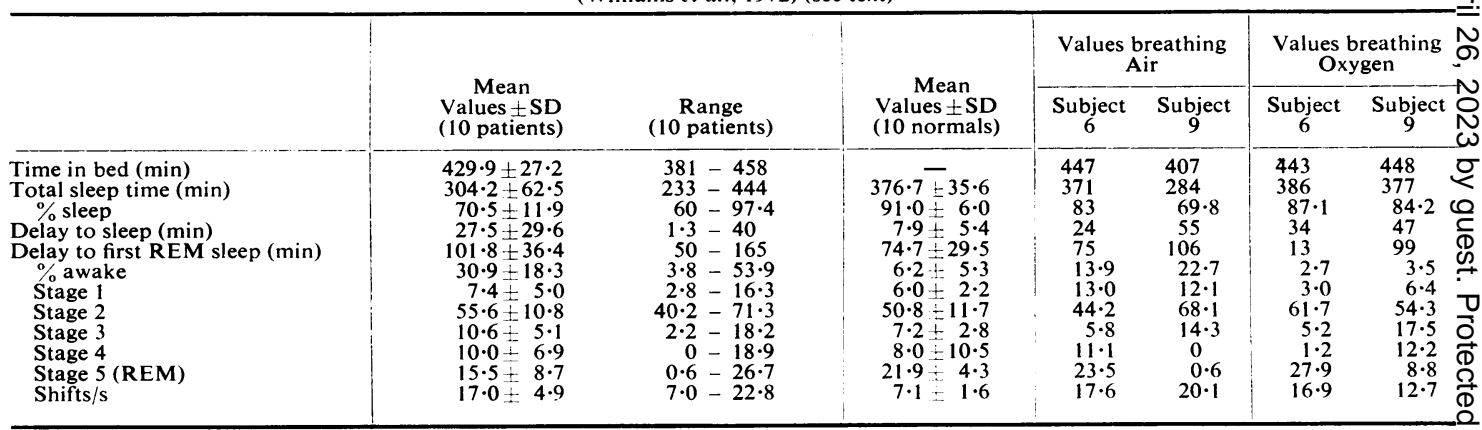

Also shown are the individual data for subjects 6 and 9 breathing air and breathing oxygen at 2 litres min ${ }^{-1}$ by nasal cannulae. 
The only consistent change produced by oxygen therapy in the two patients studied was a marked reduction in time spent awake from 13.9 and $22.7 \%$ to 2.7 and $3.5 \%$. Patient 9 had marked increases in stages 4 and 5 REM sleep but stage 4 sleep decreased in patient 6 with only a small increase in stage 5 REM sleep.

Blood sampling, which involved the experimenter entering the room and working in proximity to the patient, did not substantially alter the patients' sleep and the number of occasions on which the subjects awoke before or during the blood sampling procedure averaged approximately two occasions per night out of an average number of 18 blood samples.

\section{DISCUSSION}

The observed mean fall of arterial $\mathrm{Po}_{2}$ by $0.67 \mathrm{kPa}$ (Table I) during sleep in our patients is consistent with similar observations in normal man (Robin et al., 1958; Sieker et al., 1960; Bristow et al., 1969; Koo et al., 1975). The mean rise of $\mathrm{PCO}_{2}$ of $0.23 \mathrm{kPa}$ during sleep in our patients is less than that observed by other workers who have shown that $\mathrm{PCO}_{2}$ rises on average by $0.37-0.86 \mathrm{kPa}$ during sleep in normal subjects (Mangold et al., 1955; Birchfield et al., 1958; Robin et al., 1958; Bülow, 1963; Bristow et al., 1969; Koo et al., 1975). Our observations on changes in $\mathrm{PCO}_{2}$ during sleep are contrary to Robin's (1958) suggestion that patients with chronic respiratory failure, because they have a diminished ventilatory response to $\mathrm{CO}_{2}$, will develop more marked hypercapnia in sleep than normal subjects. We have been unable to confirm Koo's finding (Koo et al., 1975) in a less severely disabled group of patients with chronic ventilatory failure that $\mathrm{PCO}_{2}$ rises more during sleep than in normal subjects. This is almost certainly related to the way in which the comparisons have been made in the two studies. We have calculated a mean $\mathrm{PCO}_{2}$ value for sleep in each of our patients from all the blood gas estimates (average no. 14) obtained during the study, whereas Koo et al. compared only the maximal rise in $\mathrm{PCO}_{2}$ in their patients during sleep with the maximal rise in controls. Since many of their patients had large rises in $\mathrm{PCO}_{2}$ during REM sleep this would account for the marked differences obtained in their study. In our study, 18 samples were obtained during REM sleep breathing air and none showed the presence of marked hypercapnia. However, the two peaks of $\mathrm{PaCO}_{2}$ occurring when patient 6 was breathing oxygen (Fig. 1) both occurred in REM periods although this was not so for patient 9. Many of our patients had less than normal REM sleep (Table II), and our presentation of the results for each individual as mean $\mathrm{PCO}_{2}$ during sleep more accurately represents the overnight blood gas status in our patients than the single observation of maximal $\mathrm{PCO}_{2}$ (Koo et al., 1975).

When the mean $\mathrm{Po}_{2}$ and $\mathrm{PCO}_{2}$ values for our patients before and during sleep are plotted on an $\mathrm{O}_{2}-\mathrm{CO}_{2}$ diagram (Rahn and Fenn, 1955) with an assumed respiratory quotient of 0.82 (Fig. 2) we find a rise in the alveolar-arterial oxygen partial pressure difference in the majority of patients. This confirms previous observations (Koo et al., 1975) that hypoxaemia in most of these patients is due to a combination of hypoventilation and ventilation-perfusion inequality.

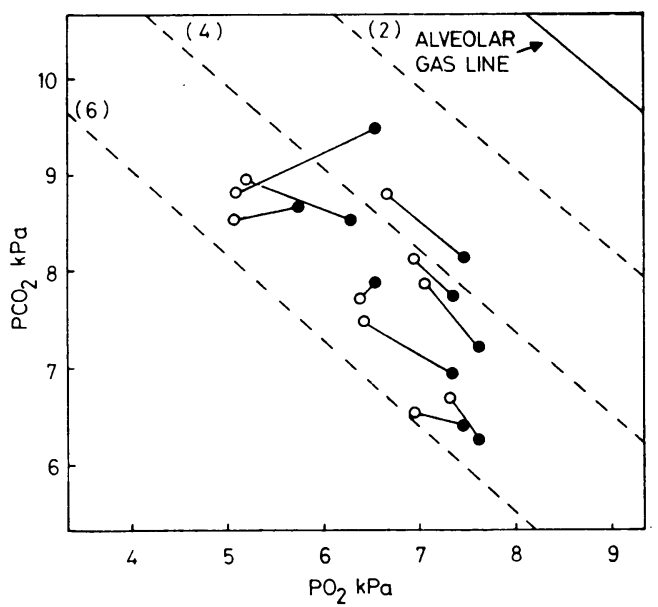

FIG. 2. $\mathrm{O}_{2}-\mathrm{CO}_{2}$ diagram with the alveolar gas line and hatched lines to indicate alveolar-arterial $\mathrm{O}_{2}$ differences of 2,4 , and $6 \mathrm{kPa}$ drawn in. The alveolar gas line is derived from the alveolar gas equation $\mathrm{PAO}_{2}=\mathrm{P}_{\mathrm{I}_{2}}-\mathrm{PACO}_{2}$ $\left[\mathrm{F}_{\mathrm{IO}}+\left(\mathrm{I}-\mathrm{F}_{\mathrm{IO}} / R\right)\right]$, assuming $R=0.82$ and $\mathrm{PACO}_{2}=$ $\mathrm{PaCO}_{2}$. (O) controls; (○) mean sleep $\mathrm{PO}_{2}$ and $\mathrm{PCO}_{2}$ for the 10 patients. The majority of patients show an increase in $\mathrm{A}-\mathrm{a} \mathrm{DO}_{2}$ with sleep, indicating a worsening $V / Q$ ratio.

Our finding in these patients with chronic ventilatory failure that the mean fall in $\mathrm{Po}_{2}$ is similar to and the mean rise in $\mathrm{PCO}_{2}$ less than the changes found in normal subjects during sleep requires explanation. These patients were all extremely hypoxic, and during sleep with the development of hypoventilation and, in most cases, ventilation-perfusion imbalance the hypoxia worsened. If the hyperbolic relationship between ventilation and $\mathrm{PO}_{2}$ (Lloyd, Jukes, and Cunningham, 1958; Weil et al., 1970), which is found in awake man, applies during sleep then falls in $\mathrm{PO}_{2}$ of the order we have found would constitute a significant additional drive to ventilation in our 
severely hypoxic patients whereas similar falls in $\mathrm{Po}_{2}$ in normoxic man would have little or no effect on ventilation (Lloyd et al., 1958). This added ventilatory drive would tend to limit the fall in $\mathrm{Po}_{2}$ and rise in $\mathrm{PCO}_{2}$ which would otherwise occur. The little evidence in man on the hypoxic drive to breathing during sleep suggests that, in contrast to the diminished ventilatory response to $\mathrm{CO}_{2}$ found in sleep, the hypoxic drive is unaffected (Reed and Kellogg, $1960 \mathrm{a}$ and b). Also there are animal experiments (Guazzi and Freis, 1969) showing that abolition of peripheral chemoreceptor activity by sino-aortic deafferentation exacerbates the hypoxaemia and hypercapnia of sleep, thus suggesting that chemoreceptor activity may be necessary to limit the hypoventilation of natural sleep.

There are two additional findings in our study which support our hypothesis that hypoxaemia and hypercapnia are limited in these patients by the presence of an active hypoxic drive to breathing. The $\mathrm{PCO}_{2}$ tended to rise less or even fall (Table I) in these patients who were most hypoxic during sleep. It is reasonable to suggest that the most hypoxic patients, by virtue of the hyperbolic nature of the $\mathrm{VE} / \mathrm{Po}_{2}$ relationship, had a greater hypoxic drive to breathing and were most likely to limit or reverse the expected rise in $\mathrm{PCO}_{2}$ during sleep. The second finding in support of our hypothesis is the effect of oxygen breathing on blood $\mathrm{PCO}_{2}$ tensions during sleep in the two patients with and without hypoxic drives to breathing (Fig. 1). Patient 6, who was shown to have a hypoxic drive to breathing when awake, developed marked hypercapnia and respiratory acidosis when his $\mathrm{PO}_{2}$ was restored to normal levels during sleep. This would be consistent with the inhibition of his hypoxic drive to breathing and a resultant hypoventilation. In contrast, patient 9, who had no demonstrable hypoxic drive to breathing, developed no more $\mathrm{CO}_{2}$ retention or acidosis during sleep, when restored to normoxia by oxygen breathing, than when he was hypoxic breathing air.

If our hypothesis that the unexpected change in blood gas tensions during sleep in these patients is due to hyperventilation brought about by an active hypoxic drive to breathing is correct, then this hyperventilation, in these patients with severe respiratory disability, may be the reason for the poor sleep patterns which we and others (Koo et al., 1975) have recorded in them (Table II). Oxygen therapy would be the obvious solution to this sleep disturbance, and our limited experience with two patients would suggest that the quality of sleep does improve (Table II) although we have yet to demonstrate that this is due to relief of hyperventilation alone. The use of hypnotics in such patients does not seem to produce any greater rise in $\mathrm{PCO}_{2}$ than natural sleep (Gaddie et al., 1972).

Long-term oxygen therapy is now used in then treatment of patients with cor pulmonale where it has been shown to diminish the polycythaemia, pul monary hypertension, and number of episodes of cardiac failure in patients with this condition (Stark $\vec{?}$ Finnegan, and Bishop, 1972; Anderson et al., 1973: Leggett et al., 1976). Oxygen therapy is given fow 15 hours per day at a flow rate of $21 / \mathrm{min}$ by nasa catheters (Leggett et al., 1976), all patients receiving oxygen during sleep. If the range of change in $\mathrm{PCO}_{2}$ and $\mathrm{pH}$ during sleep in these patients with oxygen therapy is as great as that observed in our two patients ${ }_{0}$ then it may be that hypercapnia and acidosis durings oxygen therapy at night will be factors influencing outcome in these patients. We would suggest that future trials of long-term oxygen therapy shouldo include in their assessment procedure some measure $\frac{\Phi}{3}$ ment either of the hypoxic drive to breathing or of the blood acid-base changes during sleep while breathing? oxygen. In this way, it will be possible to assesse whether large changes in $\mathrm{PCO}_{2}$ and $\mathrm{H}^{+}$during sleeps are deleterious and, if so, allow the selection of the most appropriate inspired oxygen concentration fof these patients at night.

\section{REFERENCES}

Alexander, J. K., West, J. R., Wood, J. A., and Richards, D. W. (1955). Analysis of the respiratory response to carbon dioxide inhalation in varying clinical states of hypercapnia, anoxia and acid-base derangement? Journal of Clinical Investigation, 34, 511.

Anderson, P. B., Cayton, R. M., Holt, P. J., and Howard옹 P. (1973). Long-term oxygen therapy in cor pulg monale. Quarterly Journal of Medicine, 42, 563.

Bellville, J. W., Howland, W. S., Seed, J. C., and Houde R. W. (1959). The effect of sleep on the respiratory response to carbon dioxide. Anaesthesiology, 20, 6280

Birchfield, R. I., Sieker, H. O., and Heyman, A. (1958). Alterations in blood gases during natural sleep ang narcolepsy. Neurology, 8, 107.

Bristow, J. D., Honour, A. J., Pickering, T. G., an Sleight, P. (1969). Cardiovascular and respirator changes during sleep in normal and hypertensives subjects. Cardiovascular Research, 3, 476.

Bülow, K. (1963). Respiration and wakefulness in man Acta Physiologica Scandinavica, Supplement, 209.

Evans, J. I., Lewis, S. A.,' Gibb, I. A. M., and Cheetham M. (1968). Sleep and barbiturates: some experimento and observations. British Medical Journal, 4, 291.

Flenley, D. C., Franklin, D. H., and Millar, J. S. (1970).? The hypoxic drive to breathing in chronic bronchitis and emphysema. Clinical Science, 38, 503.

Gaddie, J., Legge, J. S., Palmer, K. N. V., Petrie, J. C., an $\Phi$ Wood, R. A. (1972). Effect of nitrazepam in chronie्ष् obstructive bronchitis. British Medical Journal, 2, $688 \Omega$ 
Guazzi, M. and Freis, E. D. (1969). Sino-aortic reflexes and arterial $\mathrm{pH}, \mathrm{PO}_{2}$, and $\mathrm{PCO}_{2}$ in wakefulness and sleep. American Journal of Physiology, 217, 1623.

Honda, Y. and Natsui, T. (1967). Effect of sleep on ventilatory response to $\mathrm{CO}_{2}$ in severe hypoxia. Respiration Physiology, 3, 220.

Koo, K. W., Sax, D. S., and Snider, G. L. (1975). Arterial blood gases and pH during sleep in chronic obstructive pulmonary disease. American Journal of Medicine, $58,663$.

Leggett, R. J. E., Cooke, N. J., Clancey, L., Leitch, A. G., Kirby, B. J., and Flenley, D. C. (1976). Long-term domiciliary oxygen therapy in cor pulmonale complicating chronic bronchitis and emphysema. Thorax, 31, 414.

Lloyd, B. B., Jukes, M. G. M., and Cunningham, D. J. C. (1958). The relationship between alveolar oxygen pressure and the respiratory response to carbon dioxide in man. Quarterly Journal of Experimental Physiology, 43, 214.

Mangold, R., Sokoloff, L., Conner, E., Kleinerman, J., Therman, P. O. G., and Ketty, S.S. (1955). The effects of sleep and lack of sleep on the cerebral circulation and metabolism of normal young men. Journal of Clinical Investigation, 34, 1092.

Rahn, H. and Fenn, W. O. (1955). A Graphical Analysis of Respiratory Gas Exchange. American Physiological Society, Washington D.C.

Rechtschaffen, A. and Kales, A., eds. (1968). Manual of Standardised Terminology, Techniques and Scoring System for Sleep Stages of Human Subjects. National Institute of Neurological Diseases and Blindness, Bethesda, Maryland.

Reed, D. J. and Kellogg, R. H. (1958). Changes in respiratory response to $\mathrm{CO}_{2}$ during natural sleep at sea level and altitude. Journal of Applied Physiology, 13, 325. and - (1960a). Effect of sleep on hypoxic stimulation of breathing at sea level and altitude. Journal of Applied Physiology, 15, 1130.

and - (1960b). Effect of sleep on $\mathrm{CO}_{2}$ stimulation of breathing in acute and chronic hypoxia. Journal of Applied Physiology, 15, 1135.

Robin, E. D. (1958). Some interrelations between sleep and disease. Archives of Internal Medicine, 102, 669.

Robin, E. D., Whaley, R. D., Crump, C. H., and Travis, D. M. (1958). Alveolar gas tensions, pulmonary ventilation and blood $\mathrm{pH}$ during physiologic sleep in normal subjects. Journal of Clinical Investigation, 37, 981 .

Sieker, H. O., Heyman, A., and Birchfield, R. I. (1960). The effects of natural sleep and hypersomnolent states on respiratory function. Annals of Internal Medicine, 52, 500.

Stark, R. D., Finnegan, P., and Bishop, J. M. (1972) Daily requirement of oxygen to reverse pulmonary hypertension in patients with chronic bronchitis. British Medical Journal, 3, 724

Townsend, R. E., Prinz, P. N., and Obrist, W. D. (1973). Human cerebral blood flow during sleep and waking. Journal of Applied Physiology, 35, 620.

Weil, J. V., Byrne-Quinn, E., Sodal, I. E., Frisen, W. O., Underhill, B., Filley, G. F., and Grover, R. F. (1970). Hypoxic ventilatory drive in normal man. Journal of Clinical Investigation, 49, 1061

Williams, R. I., Karacan, I., Thornby, J. I., and Salis, P. J. (1972). The electroencephalogram sleep patterns of middle-aged males. Journal of Nervous and Mental Disease, 154, 22.

Requests for reprints to: Dr. A. G. Leitch, Department of Medicine, Royal Infirmary, Edinburgh, EH3 9YW. 